TERRA. Revista de Desarrollo Local e-ISSN: 2386-9968

Número 9 (2021), 227-232

DOI 10.7203/terra.9.22887

IIDL - Instituto Interuniversitario de Desarrollo Local

\title{
Reseña. El colapso de los microcréditos en la cooperación al desarrollo
}

\author{
Antonio Valera Lozano \\ Departamento de Geografía (Uniuversitat de València, España) \\ antonio.valera@uv.com
}

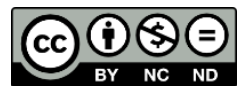

Esta obra se distribuye con la licencia Creative Commons

Reconocimiento-NoComercial-SinObraDerivada 4.0 Internacional 


\section{SECCIÓN RESEÑAS}

\section{Reseña. El colapso de los microcréditos en la cooperación al desarrollo}

Resumen: El autor analiza de forma crítica el papel de los microcréditos en la cooperación al desarrollo desde sus inicios, en los años 70 del siglo XX, hasta la actualidad. En los nueve capítulos que componen la obra trata de desmontar cada uno de los argumentos que se han defendido en relación a las microfinanzas como la solución a la pobreza y que han situado a éstas como una de las herramientas de cooperación que más dinero han recibido. El autor hace hincapié en la falta de estudios y evaluaciones rigurosas que respalden los presuntos efectos positivos para la población más pobre de los microcréditos. Las escasas evaluaciones rigurosas que sí se han realizado, según el autor, parecen indicar que las microfinanzas en países en desarrollo, no solo no tienen efectos beneficiosos sobre la población a los que van dirigidos, sino que incluso, en ocasiones, derivan en mayor vulnerabilidad y pobreza. El argumento principal de esta obra es que los microcréditos no están concebidos como verdaderas herramientas para la erradicación de la pobreza, sino que son un nuevo avance del sistema financiero global capitalista neoliberal para incrementar sus beneficios y cartera de clientes.

Palabras clave: capitalismo, cooperación, desarrollo sostenible, microcréditos, pobreza.

Recibido: 15 de diciembre de 2021

Devuelto para revisión: -

Aceptado: 20 de diciembre de 2021

Referencia / Citation:

Valera, A. (2021). Reseña. El colapso de los microcréditos en la cooperación al desarrollo. TERRA. Revista de Desarrollo Local, (9), 227-232. DOI 10.7203/terra.9.22887 


\section{Carlos Gómez Gil \\ EL COLAPSO DE LOS MICROCRÉDITOS EN LA COOPERACIÓN AL DESARROLLO}

Madrid (España). Catarata. IUDC-UCM, 2016, 197 pp.

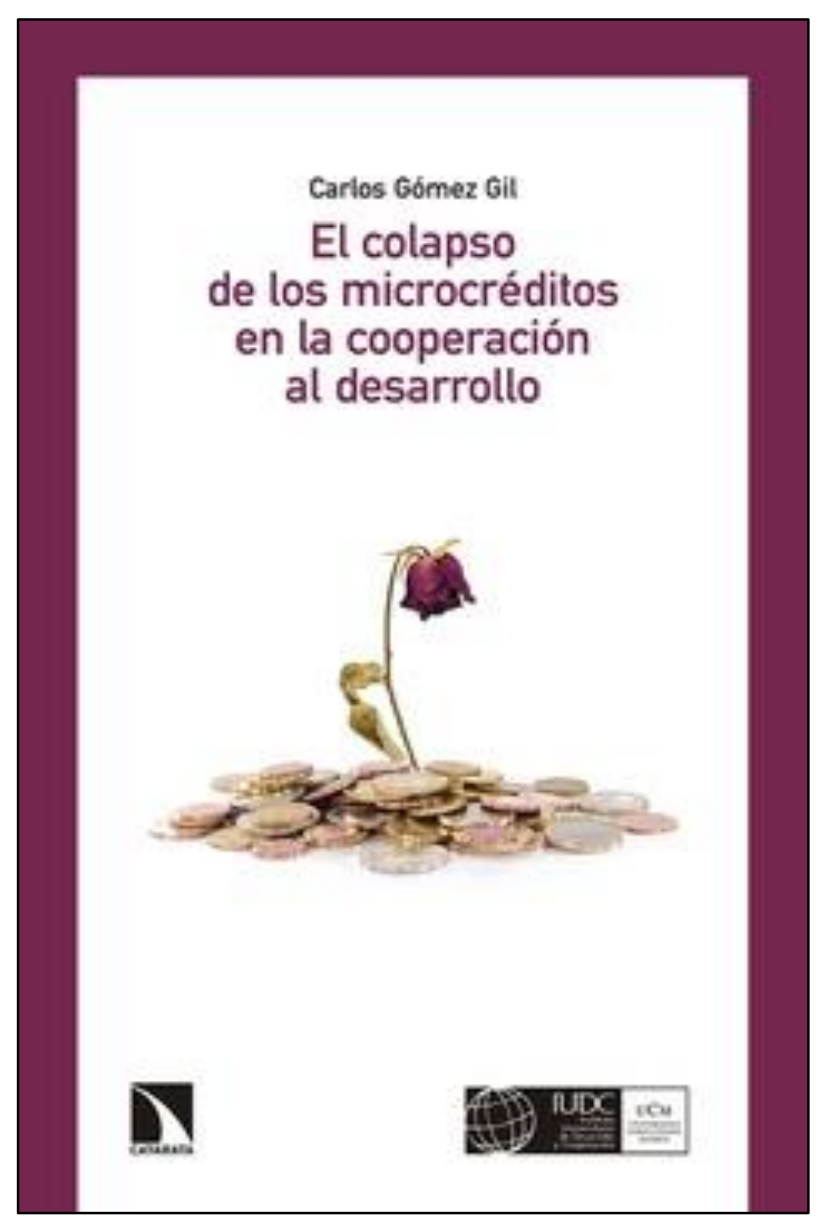

Los contenidos de la obra que reseñamos a continuación muestran bien el desengaño respecto a la efectividad y conceptualización de una de las "herramientas estrella" de la cooperación al desarrollos durante las últimas décadas: los microcréditos. La crisis financiera global que detonó en 2008 poniendo patas arriba las economías muchos países y comunidades, provocó, entre otros efectos colaterales, una reducción enorme de los fondos destinados a la cooperación internacional (especialmente la española) y, con ello una necesidad de revisión profunda de los fondos gastados hasta entonces y de su efectividad real. Es en este marco en el que se realiza esta obra, aunque el texto y la trayectoria del autor hace evidentes que ya llevaba varios años dando la voz de alarma sobre la inefectividad, cuando no efecto perverso sobre la pobreza, de las microfinanzas. Las Instituciones Microfinancieras (IMF) basan su actividad en proporcionar créditos de muy pequeña cuantía (microcréditos) entre la población más pobre y vulnerable, que por esa misma situación no tendría acceso a los medios de financiación convencionales (bancos, cajas de ahorro, etc.). Esas pequeñas cantidades servirían para que sus receptores pudieran poner en marcha pequeños negocios que les permitieran salir de su situación de marginalidad, vulnerabilidad y pobreza. A través del análisis de los pocos trabajos rigurosos sobre los microcréditos que existen y de un seguimiento del papel de las microfinanzas en aquellas regiones en las que han tenido más presencia, dentro de los proyectos de cooperación al desarrollo, el autor va desmontando cada uno de los preceptos que han tratado de avalar los presuntos efectos positivos de esta herramienta. Además, plantea profundas dudas sobre la adecuación e incluso moralidad de muchos de los principales argumentos a favor de los microcréditos.

El primer capítulo está dedicado a analizar la siutación actual y debate sobre los micrecréditos. Enumera aquí los principales argumentos de los defensores de los microcréditos, que después desmontará. Esto es: que son instrumentos ideales para que los pobres, al solicitarlos, salgan de la situación de pobreza extrema; que en su mayor parte son utilizados por mujeres; que ponen la solución a la pobreza extrema en manos de los propios pobres, al insertarse de lleno en el capitalismo; que, al no ser limosnas ni 
subsidios son más dignos para los que los reciben; que, al no dirigirse a sectores concretos, sirven para financiar actividades en áreas prioritarias para la población. El autor es contundente al respecto, y afirma que "los microcréditos representan uno de los grandes fracasos entre los instrumentos de cooperación mundial que se han impulsado en las últimas décadas, siendo utilizados en no pocas ocasiones de forma fraudulenta para impulsar políticas e intervenciones neoliberales radicalmente contrarias a los beneficios de sus destinatarios".

El segundo capítulo se centra en los conceptos de microcréditos, microfinanzas e instituciones microfinancieras. Da como definición a los microcréditos: "un crédito pequeño a través del cual una organización microfinanciera proporciona una pequeña cantidad de dinero a una persona pobre, asumiendo el deudor la obligación de devolver la cantidad prestada más los intereses acordados y los gastos financieros aplicados". Las microfinanzas serían un concepto más amplio, qu no solo se refiere al crédito sino también a otros servicios financieros especializados. Por último, las Instituciones Microfinancieras (IMF) serían las organizaciones especializadas en las microfinanzas. Según el autor, estas instituciones han desarrollado una amplia batería de exigencias, avales y procedimientos para garantizarse el cobro de los créditos, que van desde la socialización de los mismos, a seguros post-mortem e incluso la extorsión a través de sicarios.

El capítulo 3 analiza los inicios y extensión de las microfinanzas y los microcréditos, desde sus antecedentes en Bangladesh en los 70. El modelo se extenderá rápidamente por otros países de la región y será incentivado y aplaudido a nivel internacional, según el autor, por ser una extensión de las políticas neoliberales de la Escuela de Chicago y contribuir a legitimar el Capitalismo. Se hace hincapié en que el interés ideológico puede haber tenido más peso en la extensión de esta herramienta que la propia preocupación por erradicar la pobreza. El autor dedica bastante espacio a analizar el papel de Mohammad Yunus (auténtico gurú de los microcréditos y premio nobel de la paz) y el instrumento creado por él, el Grameen Bank, que pese a sus presuntos éxitos iniciales se ha visto envuelto en controversias y cuestionamientos (se calcula que el 95\% de sus prestatarios no han logrado salir de la situación de pobreza). El resto del capítulo se centra en analizar la presencia de los microcréditos en la cooperación española, estableciendo que han sido muy utilizados y poco cuestionados. A continuación, el autor comenta las insuficiencias y corrupciones en relación a las microfinanzas que parece han sido puestos en evidencia por los pocos análisis rigurosos que se han centrado en ellas. Se mencionan como algunos de estos problemas detectados: la falta de seguimiento, el desvio de fondos a paraísos fiscale o su utilización para programas controvertidos (por ejemplo antiabortistas).

En el cuarto capítulo, el autor se centra, precisamente, en la crisis y desmoronamiento de las microfinanzas en el mundo. La crisis financiera mundial hace que las instituciones de cooperación al desarrollo reduzcan en general su presupuesto y revisen sus actuaciones. Por otro lado, al afectar de forma directa a la población más desfavorecida, esta misma crisis inicia una cadena de morisidad, impagos y reacciones que pondrá en evidencia a las IMFs. Se cita y explica la toma de conciencia contra los microcréditos en Andhra Pradesh (India), Marruecos, Bangladesh o Bosnia-Herzegovina, entre otros. El autor analiza tres grandes aspectos que incidieron en el cuestionamiento y colapso de los microcréditos: el movimiento "no pago" con el que líderes locales promovieran que los deudores de microcréditos, agobiados por los altos intereses e imposibilidad de pagar, dejaran de abonar sus deudas a las IMFs; los beneficios exorbitados de directores y ejecutivos de varias IMFs obtenidos por la salida a bolsa de éstas; la detección de un incremento de suicidios (especialmente de mujeres) entre los deudores morosos de las IMFs; la 
identificación de casos de servidumbre forzada como forma de pago a microcréditos en Pakistán; el desvío de fondos de cooperación a paraisos fiscales en el Grameen Bank (una de las IMF de referencia). Según el autor, pese a ese movimiento global progresivo de rechazo, la cooperación española se ha mantenido en general ajena al debate, en parte por los intereses económicos creados, pero también por cierto "complejo de culpa" del mundo académico que ha estado apoyando a los microcréditos durante décadas.

El quinto capítulo se dedica a exponer o reincidir en las razones y justificaciones por las que las microfinanzas han sido tan apoyadas por la comunidad internacional. Según el autor "los microcréditos han permitido mantener los niveles estadísticos de la ayuda sin menoscabo de una garantía sobre los retornos financieros" y, por tanto, que ha sido más rentable prestar dinero que se cobrará con intereses que invertir directamente en salud, nutrición, educación básica, etc. para la población pobre. Además, el argumento de que los pobres deben ser responsables de su desarrollo (gracias a su "emprendimiento" con microcréditos) anula las responsabilidades de gobiernos e instituciones internacionales. Por último, aparte de apoyar los postulados ideológicos neoliberales tan presentes en las políticas nacionales e internacionales en las últimas décadas, los microcréditos han servido como excusa para extender la economía bancaria y financiera entre los más pobres, excluidos hasta entonces de ese sistema, con el objetivo principal de aumentar los beneficios económicos.

Frente a esas razones que pueden estar detrás del apoyo y expansión internacional de los mircrocréditos, el autor dedica el capítulo seis a exponer los problemas y limitaciones más importantes de las microfinanzas. En primer lugar, los microcréditos presentan un diseño incorrecto como instrumentos de desarrollo al reducir la misma a una simple variable económica, ignorar los procesos de acumulación por desposesión que están detrás y poner la responsabilidad de dejar de ser pobres sobre la espalda de los más vulnerables. En segundo lugar, al apoyar normalmente actividades de subsistencia, informales y poco viables, los microcréditos han desviado fondos que podrían haberse destinado a pequeñas y medianas empresas locales que pagan impuestos, pueden innovar, son más eficientes y pueden generar empleos y, por tanto, mejorar de verdad las economías locales. El tercer argumento contra las microfinanzas es que, en lugar de empoderar a las mujeres solicitantes, en muchas ocasiones agravan su situación y vulnerabilidad, puesto que muchas veces son en realidad hombres los que gestionan el préstamo recibido y la responsabilidad de pagar la deuda se añade a la de mantener y proteger a los hijos y llevar la economía familiar. El cuarto argumento es que la mayor parte de los microcréditos se destinan al consumo básico y la subsistencia, con lo que es difícil que permitan a los deudores salir de una situación de pobreza estructural, sino más bien al contrario. El quinto argumento se centra en que, a diferencia de las bajísimas tasas de morosidad pregonadas por las IMF, éstas en realidad se sitúan entre el 22 y el 69\%, lo que hace a las microfinanzas un intrumento de alto riesgo. Este riesgo lleva al autor a su sexto argumento, que es que para compensarlo las IMF han consolidado prácticas cuestionables como interses abusivos (entre el 20 y el 229\%). También en esta línea se citan otras prácticas cuestionables detectadas como dudosos procedimientos de evaluación, desvío de fondos, especulación, etc. Para finalizar el capítulo se presentan varios casos, uno de ellos relacionado con una ONG española, en la que el resultado de los microcréditos no ha sido la reducción de la pobreza, sino el beneficio de las IMFs.

El octavo capítulo del libro está dedicado a aportar alternativas a las microfinanzas. Según el autor, estas propuestas han de ser solidarias y efectivas en la lucha contra la pobreza, han de evitar cargar de deudas a los receptores y no destinarse a financiar la subsistencia, porque para eso último son más efectivos programas de renta básica, alimentos o de 
bienes de primera necesidad. Se proponen, en esa línea: microcréditos sociales, asesoramiento financiero sostenible y comunidades de autogestión financiera; bancos estatales y municipales de desarrollo; cooperativas financiera; recuperar fórmulas tradicionales de solidarirad; economía social y formas comunales de producción; fomento de empleo público para los más pobres; fórmulas adaptadas y específicas para cada grupo social y región.

El noveno y último capítulo sirve al autor para realizar una serie de consideraciones finales. Según él, la industria de las microfinanzas ha sido un paso más en la expansión del capitalismo global, y no tenía como objetivo real la reducción de la pobreza. Frente a la visión de las microfinanzas como una fórmula milagrosa, su aplicación en colectivos vulnerables y en condiciones inadecuadas tiene más bien el efecto de aumentar su exclusión social. Los microcréditos se basan en la filosofía perversa de que la responsabilidad sobre el desarrollo y supervivencia de los pobres es de estos mismos individuos pobres, no de las instituciones y organismos públicos. Décadas de recurrir a las microfinanzas en programas de cooperación al desarrollo han motivado que en la actualidad no solo haya que enfrentarse al desafío de reducir la pobreza, sino también la deuda generada por los microcréditos.

Se trata de un trabajo bien fundamentado documentalmente que saca a la luz algunas contradicciones que han tenido los programas de cooperación al desarrollo cuando, por delante de los objetivos necesarios de reducir la pobreza, la vulnerabilidad y la exclusión social, se han puesto otros intereses más espurios y unos objetivos paralelos de justificación ideológica neoliberal y de negación de responsabilidades. Pese a que, en ocasiones, el texto puede redundar demasiado en algunos temas y se le podría achacar cierta componente ideológica contraria a la que él mismo critica, se trata de un estudio necesario, bien estructurado y que puede ser de gran interés para cualquier línea de trabajo académico o práctico relacionado con la cooperación al desarrollo.

Antonio Valera Lozano

Departamento de Geografía (Universitat de València)

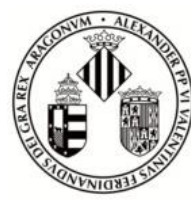

VNIVERSITAT (E) VALÈnCIA 